\title{
On Human Evolution
}

\author{
William E. H. Harcourt-Smith
}

Published online: 20 August 2010

(C) Springer Science+Business Media, LLC 2010

Keywords Human evolution P Paleoanthropology · Hominins

As a paleontologist working on human evolution, one of those inevitable questions that always comes up with my colleagues is, "what's so special about us?" Any fair-minded biologist on the planet will tell you that all living things are special in their own way, each species unique in its possession of beautifully particular characters and adaptations. Humans are just another animal they would say, and in most cases they'd be right. Yet there is still this nagging feeling that we are different. Even as a scientist, it is extremely seductive to play up our distinctiveness from the rest of the natural world. Newly discovered fossils of our ancestors often make headline news or get onto the cover of prestigious journals like Nature and Science, giving their discoverers a lot of fame and attention in the process. If you add that no other living species has language, complex symbolic expression, or such a rich material culture, you have a heady mix of factors that very much drives our view of ourselves as being set apart. In many ways, this is what lies at the heart of the problematic "debate" that currently rages over scientific versus religious explanations for our origins. To some people, we are simply so different that we can't possibly have evolved from other animals.

To any scientist, this is a major problem as it indicates a form of human exceptionalism expressed as denial that we

\footnotetext{
W. E. H. Harcourt-Smith $(\square)$

Division of Paleontology, American Museum of Natural History, Department of Anthropology,

Lehman College and Graduate Center CUNY,

New York, USA

e-mail: willhs@amnh.org
}

have evolved. One can address this in many ways. A lot of people simply ignore it, but to my mind nothing beats plainly laying out the evidence for our own evolutionary past within the broader context of the history of life on this planet. That is the purpose of this special edition of Evolution: Education and Outreach. We present a series of up-to-date articles that summarize some of the most important topics in human evolution studies today. The collection is by no means definitive, and there will inevitably be some gaps, but it does clearly lay out the major lines of evidence, be they genetic, fossil-based, or archeological.

We start off with Tom Gundling's (William Patterson University) riveting account of the history of how human evolution has been studied over the last few hundred years. Apart from being a fine introduction to the field of paleoanthropology, it acts as an extremely important reminder as to how political and social attitudes of the day can often influence scientific thinking. Kieran McNulty (University of Minnesota) then sets the scene for the rest of the edition. He is a specialist on Miocene apes, creatures who flourished between 20 and 6 million years ago, and of whom only a few lineages remain. Of course one of them is our own, the hominins. If one wants to understand what were the factors and events that led to development of the hominin lineage, one has to first look at what was going on before its emergence. I myself then cover the first hominins and also present a summary of the evidence surrounding the origins of bipedal locomotion, one of our most peculiar specialities and probably the first major adaptation to occur in the hominin lineage. David Strait (SUNY Albany) follows by deftly tackling perhaps the most well-known early hominins, the australopiths (which include "Lucy") but also reviews their more enigmatic cousins, the genus Paranthropus. 
We then move on to the origins of our own genus, Homo. This is a notoriously tricky area of human evolution, and Holly Dunsworth (Northeastern Illinois University) does a fine job of reviewing the major lines of evidence for early Homo in Africa, as well as the initial spread of our genus out of Africa. We then have four wonderful papers that deal with different aspects of the latter period of human evolution. Katerina Harvati (University of Tübingen) introduces us to the Neanderthals and their possible European ancestors. The Neanderthals are arguably the most well-known and misunderstood extinct relatives of modern humans. Often portrayed as the quintessential "cave-man," they are the only fossil hominin for whom a pejorative adjective has become part of the English language. In fact, they were a large-brained and behaviorally complex species who seem to have been genetically close enough to modern humans to have interbred with them. Christian Tryon (New York University) and colleagues summarize the archeological evidence for human origins, starting with the oldest stone tools over 2.5 million years in age and ending up with the complex assemblages made by the first member of our own species, Homo sapiens. Jason Hodgson and Todd Disotell (New York University) address the increasingly important field of molecular genetics. Although fossilized specimens do not usually yield molecular material, their discipline is informing us more and more about when certain living lineages diverged from each other. Ian Tattersall (American Museum of Natural History) finishes up with an eloquent essay on the emergence of modern humans.

The last paper in this special edition is by Monique Scott (American Museum of Natural History) and discusses how human evolution is displayed and taught in museums, both today and in a historical context. Anyone thinking about displaying human evolution, whether in a classroom corner or a large-scale museum, would do well to read this insightful piece.

As a final note, I hope this special issue of $E: E \& O$ will act as an invaluable study aid to educators of all types, be they exhibit designers, high school biology teachers, or board members deciding on policy. Asking questions about our origins is one of the things that makes human, and nothing surpasses having the facts laid out for all to see.

It only remains for me to extend my thanks to all the wonderful authors who have contributed such excellent papers, and most of all, to Niles Eldredge and his editorial team at $E: E \& O$ for not only their insight and vision in creating this journal but also their considerable patience and fortitude as I assembled the various papers for this special issue. 